
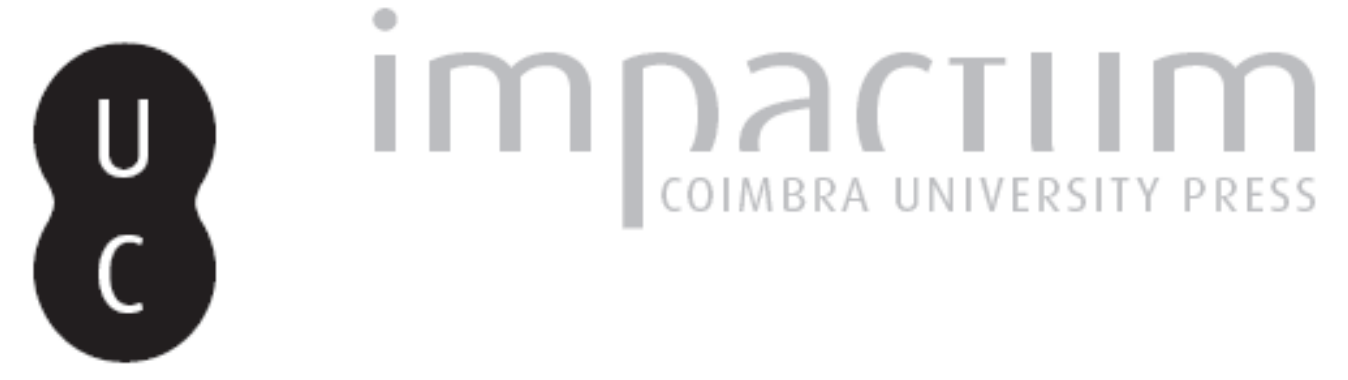

\title{
Duas epígrafes funerárias romanas do Monte de Santa Luzia (Freixo de Espada à Cinta)
}

Autor(es): $\quad$ Redentor, Armando

Publicado por: Faculdade de Letras da Universidade de Coimbra

URL persistente:

URI:http://hdl.handle.net/10316.2/37690

DOI:

DOI:http://dx.doi.org/10.14195/1647-8657_42_8

Accessed : $\quad$ 26-Apr-2023 08:31:45

A navegação consulta e descarregamento dos títulos inseridos nas Bibliotecas Digitais UC Digitalis, UC Pombalina e UC Impactum, pressupõem a aceitação plena e sem reservas dos Termos e Condições de Uso destas Bibliotecas Digitais, disponíveis em https://digitalis.uc.pt/pt-pt/termos.

Conforme exposto nos referidos Termos e Condições de Uso, o descarregamento de títulos de acesso restrito requer uma licença válida de autorização devendo o utilizador aceder ao(s) documento(s) a partir de um endereço de IP da instituição detentora da supramencionada licença.

Ao utilizador é apenas permitido o descarregamento para uso pessoal, pelo que o emprego do(s) título(s) descarregado(s) para outro fim, designadamente comercial, carece de autorização do respetivo autor ou editor da obra.

Na medida em que todas as obras da UC Digitalis se encontram protegidas pelo Código do Direito de Autor e Direitos Conexos e demais legislação aplicável, toda a cópia, parcial ou total, deste documento, nos casos em que é legalmente admitida, deverá conter ou fazer-se acompanhar por este aviso.

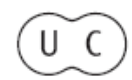


CONIMBRIGA

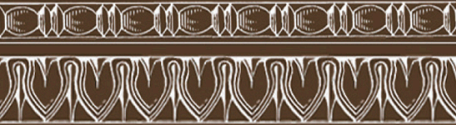

NSTITUTO DE ARQUEOLOGI

I

VOLUME XLII - 2003

A C U L D

UNIVERSIDADE DE COIMBR 
ARMANDO REDENTOR

Arqueólogo. Mestre em Arqueologia pela Universidade de Coimbra.

DUAS EPÍGRAFES FUNERÁRIAS ROMANAS DO MONTE DE SANTA LUZIA (FREIXO DE ESPADA À CINTA)

"Conimbriga" XLII (2003) p. 213-223

Resumo: Apresenta-se o Monte de Santa Luzia (Freixo de Espada à Cinta) como sítio arqueológico da época romana e estudam-se as duas únicas epígrafes que dele procedem.

Relativamente a uma delas, conhecida desde os anos 70, faz-se uma revisão das leituras anteriormente propostas, reafirmando-se o seu carácter latino. A outra é pela primeira vez dada a conhecer, na sequência da sua recente descoberta. Marginalmente, também se dá notícia de uma escultura zoomórfica (berrão) identificada na mesma altura em que se detectou esta nova epígrafe.

ABSTRACT: Monte de Santa Luzia (Freixo de Espada à Cinta) is presented as being an archaeological site of the roman period and the two sole epigraphs that were found there are the object of this study.

One of the refered epigraphs is known since the 1970's — a revision of the priorly proposed interpretations is made, reafirming it's latin character. The other is presented for the first time as a consequence of it's recent finding. Marginally, it is also noted that a zoomorphic sculpture - boar - was identified at the same time this new epigraph was discoverd. 
(Página deixada propositadamente em branco) 


\section{DUAS EPÍGRAFES FUNERÁRIAS ROMANAS DO MONTE DE SANTA LUZIA (FREIXO DE ESPADA À CINTA)}

Um monte suavemente cónico, sem grande notoriedade fisiográfica relativamente ao conglomerado de elevações que ondulam a depressão de Freixo de Espada à Cinta, coroado por um amendoal (fig. 1), constitui um dos sítios arqueológicos mais interessantes desta unidade geográfica ${ }^{1}$.

A sua notoriedade foi ressaltada, essencialmente, por J. Santos Júnior (1963; 1975, p. 403-418; 1977; 1978; 1981; 1983; 1985) devido ao elevado número de esculturas zoomórficas que lhe estavam associadas, mas a ausência de defesas nega a classificação como povoado fortificado introduzida por este investigador - inclusive na própria denominação do sítio: Castro de Santa Luzia ou Castro do Monte de Santa Luzia —, a qual, no entanto, virá a ser consentida por outros (Silva 1986, p. 103, n. ${ }^{\circ} 824$; Marques 1991, p. 398).

Trata-se de um grande povoado aberto, que F. S. Lemos (1993, IIa, p. 159-161) admite poder ter sido um uicus que também teria desempenhado as funções de mansio e que, recentemente, C. Cruz (2000, p. 220 e 424) sugere ter encabeçado uma possível ciuitas centrada no espaço geográfico definido pela depressão de Freixo de Espada à Cinta - duas interpretações diversas que valorizam o seu posicionamento geoestratégico, relacionado com a proximidade a um eixo viário romano (Carril Mourisco) e à confluência dos rios Douro e Huebra, e as próprias evidências arqueológicas.

Os vestígios superficiais, sobretudo fragmentos de cerâmica romana de construção e doméstica, escórias de ferro, mós manuárias

1 Monte de Santa Luzia, freguesia de Freixo de Espada à Cinta, concelho de Freixo de Espada à Cinta. CMP 1:25 000: n. ${ }^{\circ}$ 132. Coordenadas geográficas (WGS 84): latitude $=41^{\circ} 07^{\prime} 03.13^{\prime}$ 'N ; longitude $=6^{\circ} 47^{\prime} 26.80^{\prime}$ ' $\mathrm{W}$; altitude $=531 \mathrm{~m}$. 
e abundantes elementos pétreos relacionáveis com estruturas de alvenaria arruinadas, espalham-se pelo topo e vertentes suaves do monte, numa área aproximada de 7 ha. Para além do numeroso lote de esculturas zoomórficas - cerca de uma trintena (cf. Álvarez-Sanchís 1999, p. 367-369) — procedentes deste sítio, bem como do cabeço conhecido por Coraceira, que se levanta imediatamente a sul, apenas separado por discreta linha de água, há também todo um conjunto de outros interessantes materiais que foram sendo recolhidos na sequência dos cíclicos trabalhos agrícolas. Desta colecção, na posse da família proprietária do amendoal de Santa Luzia (Santos Júnior 1975, p. 404-405; Marques 1991, p. 398-399), constam: um número considerável de numismas de bronze, entre os quais se identificam algumas cunhagens baixo-imperiais; bronzes figurativos: haste e pé calçado com sandália, presumíveis fragmentos de estatuetas, o primeiro pertencente a representação de bovídeo e o segundo a figura feminina; objectos de adorno diversos: anéis de ferro e um de bronze com representação de escorpião gravada na mesa, fíbulas, alfinetes de bronze, pedras de anel (uma com figuração de Roma) e contas de colar de pasta vítrea, uma bracelete e um camafeu com armação e argola de suspensão brônzeas que ostenta uma gravação pétrea representando a deusa Minerva; e objectos utilitários: cossoiros de xisto, pregos, um fragmento de lâmina de falcata e um pilum de ferro, e alfinetes, correntes, uma colher e um anzol de bronze.

J. Santos Júnior (1975, p. 403-404 e fig. 64, est. XVIII) também publicou um fragmento epigrafado de uma pequena estela que encontrou numa parede em que se empilhava a pedra resultante da limpeza do terreno do amendoal de Santa Luzia aquando das lavras. Não fez, então, uma satisfatória avaliação do achado, pois, apesar de ter tomado consciência de que a fotografia da peça incluída na publicação podia estar invertida, sugeriu uma interpretação incorrecta, além de incompleta: propôs a leitura SACCO para a primeira linha, sem mais acrescentar.

Reinterpretando a epígrafe a partir da fotografia invertida publicada por Santos Júnior, Barry Fell (1982, p. 142 e 147, fig. 6-8) conclui tratar-se de uma estela cujo texto, segundo ele, escrito no antigo silabismo basco, indica ser dedicada aos Laminak, criaturas míticas que continuam a povoar o imaginário popular vascão;

2 Pelo carácter misterioso que revestem não é unívoca a sua interpretação: são relatados como pequenos seres subterrâneos, monstros femininos, ou uma espécie de pitonisas ou sacerdotisas (cf. Fell 1982, p. 147; "Laminak." Encyclopedia Mythica). 
o texto, em duas linhas, seria: $L a-m i-n o-y a-r i$ / $e-t o$ $e-g i-n i^{3}$.

Acreditando que, assim sendo, se trataria de uma inscrição anterior às epígrafes romanas peninsulares, Santos Júnior (1983, p. 532) virá a aceitar a interpretação do professor de Harvard declarando:

Pode parecer chocante a interpretação e leitura feita por Barry Fell da lápide que encontrei no castro de Santa Luzia, Freixo de Espadaà-Cinta (...).

No entanto, quem ler os primeiros capítulos do livro Bronze Age America fica ciente de que tal interpretação é baseada no meticuloso estudo analítico de esquemáticos e remotos sistemas de grafia, num labor altamente meritório.

Algum do espólio arqueológico que J. Santos Júnior recolheu no Nordeste Transmontano foi legado ao Museu do Abade de Baçal, em 1976, e dele consta este fragmento epigráfico (n. ${ }^{\circ}$ de inventário: 1662) que não mereceu até ao presente qualquer esforço de revisão ${ }^{4}$, tarefa que cumprimos no intuito de o reavaliarmos enquanto documento histórico (= A - epitáfio de Bucão).

Em visita ao Monte de Santa Luzia, datada de Abril de 2001, descobrimos a parte superior de uma outra estela (= B - epitáfio de Cloutina $)^{5}$ que jazia no topo deste sítio arqueológico, à superfície, não longe do pombal arruinado que encima o relevo 6 .

3 Fell (1982, p. 147) apresenta a seguinte tradução: ‘Aos Laminak / faz ofertas de orações'.

4 Em trabalhos mais recentes que aludem ao Monte de Santa Luzia, ou a inscrição não é lembrada (Marques 1991; Cruz 2000, p. 220, n. ${ }^{\circ} 229$ ) ou é apontada a dificuldade da sua leitura (Lemos 1993, IIa, p. 160).

5 A epígrafe será, oportunamente, depositada no Museu do Abade de Baçal (Bragança).

6 Integrada na estrutura alveolar do interior do pombal, também identificámos um pequeno berrão (porco) de granito de grão fino com os membros e a cabeça amputados (fig. 4), integrável no tipo 4 de J. Álvarez-Sanchís (1999). Da sua morfologia destacam-se a linha dorsal abatida e a traseira de perfil curvo, sendo inferiormente perceptível o arranque da representação dos membros posteriores. Dimensões máximas (alt./compr./larg.): [22]/[27]/21,5. 


\section{A. Epitáfio de Bucão (fig. 2)}

Fragmento de estela funerária de granito, de que se conserva quase que exclusivamente o campo epigráfico e uma pequena listra preservados entre as duas fracturas oblíquas, com superfícies bastante desgastadas. O campo está circunscrito, superior e lateralmente, por linhas incisas, não havendo sinal de uma delimitação inferior; as linhas laterais parecem ter uma função de demarcação perimétrica da própria estela, podendo ter servido, assim, como linhas estruturantes da arquitectura decorativa do monumento, tal como nos permite perspectivar a do lado direito. Trabalho de acabamento estendido às quatro faces.

\section{Dimensões: [21]/20/10. Campo epigráfico: $8,5^{7} / 15$}

\section{BVCCO / MENTI A(nnorum) / XV}

Bucão, (filho) de Mento, de 15 anos.

Alt. letras: 1. 1: 3,1/3,8 (O=2,7); 1. 2: 3,6/3,7 (A=2,9); 1. 3: 2,4/2,9. Espaços: 1: 0,2/0,6; 2: 0,3/0,6; 3: 0/0,5.

As duas primeiras linhas, gravadas dentro do espaço epigráfico delimitado, apresentam um alinhamento simultâneo à esquerda e à direita; a última não segue qualquer alinhamento e os seus caracteres foram dispostos enviesadamente em relação aos das linhas anteriores. Estas evidências, bem como o menor módulo do último caracter da linha intermédia e dos da última, levam a supor um acrescento da menção da idade do defunto. Os caracteres, gravados de forma imprecisa, denotam acusada influência cursiva, o que dificulta a leitura do texto, sobretudo na segunda linha, na qual, além do mais, se utilizaram os nexos ME e NT. Na 1. 1: B de haste curva e panças desiguais, $\mathrm{V}$ de hastes ligeiramente arqueadas, $\mathrm{CC}$ e $\mathrm{O}$ pouco elegantes e angulosos; na 1. 2: nexo ME de hastes inclinadas e sinuosas, ultrapassando a esquerda a união com a central, e de barras indicativas do E desiguais, nexo NT de haste esquerda não formando vértice com a mediana e de barra a travar a direita, indicando o $\mathrm{T}$, I de extremidade superior encurvada para a direita, A superiormente aberto e de traço oblíquo unido à haste direita substituindo travessão; na 1. 3: X de hastes desiguais e ligeiramente curvas, tal como as do $\mathrm{V}$, que surge unido ao primeiro nexo da linha intermédia.

\footnotetext{
7 Corresponde à altura da parte delimitada pelas linhas incisas.
} 
O nome Bucco não conta com demasiados testemunhos hispânicos (cf. Abascal 1994, p. $305+C I L \mathrm{II}^{2}$ 7, 988), à semelhança do que se passa à escala imperial (cf. Kajanto 1965, p. 268); tem, no Noroeste Peninsular, um outro testemunho, saído da província de León (Villalís: $A E$ 1910, 1). M. L. Albertos (1966, p. 62-63) integra-o entre os antropónimos indígenas - aproxima-o de Buccius, cujo radical se relaciona com o indo-europeu *bhugos, na sua forma expressiva *bhukkos, bhukka com significado de 'bode, cabra' —, contudo, não será de excluir a sua pertença ao domínio latino (Kajanto 1965, p. 63 e 268).

O genitivo Menti é, segundo cremos, um hapax na antroponímia peninsular, ainda que possa ser posto em relação com os nomes Mentina/-us, cuja área de dispersão não ultrapassa as vizinhas províncias de Salamanca (Bermellar: HAE 1248 + CIRPS 19; Boada: HAE 1249 + CIRPS 21; Hinojosa de Duero: CIRPS 87; Yecla de Yeltes: CIL 5036 + CIRPS 299, HAE 1343 + CIRPS 300, ILER $6209+$ CIRPS 301) e Zamora (Moral de Sayago: CIL II 2623 + CIRPZ 89; CIL II 2625 + CIRPZ 91). Ment- foi considerado variante fonética de Mant-, radical que tem sido posto em relação com o indo-europeu *men- 'sobressair' (Palomar 1957, p. 83; Albertos 1966, p. 147), ainda que não se descarte uma outra origem no indo-europeu *men- 'pensar', *menter- 'pensador', *menti-, *mnti-, *mnto- 'pensamento' (Albertos 1966, p. 156). O antropónimo que nesta inscrição se documenta pode bem representar a base de derivação dos nomes com o mesmo radical sufixados com - $n$ - precedido da vogal - $i$-, processo frequente na antroponímia peninsular (cf. Albertos 1966, p. 293-294); esta hipótese parece-nos tanto mais plausível quanto há entre esses achados, sobretudo os salmantinos, e o que agora revemos grande proximidade geográfica.

Â falta de critérios mais seguros de datação, apoiamo-nos na paleografia para sugerir uma cronologia dos séculos II-III.

\section{B. Epitáfio de Cloutina (fig. 3)}

Parte superior de estela funerária de cabeceira semicircular, de granito, fracturada ao nível do campo epigráfico e no topo. Apresenta trabalho de acabamento em todos os lados e as arestas posteriores biseladas. Na cabeceira, o registo decorativo desenvolve-se no interior de campo ultra-semicircular rebaixado e é composto por estrela sobreposta a crescente de pontas viradas para cima; ambos os motivos foram exe- 
cutados por incisão, embora com diferentes critérios de representação: à figuração do crescente com definição dos contornos e uma linha interior opõe-se o esquematismo da estrela, gizada por simples linhas a indicar as suas (seis?) pontas. O campo epigráfico é igualmente rebaixado.

Dimensões: [29,5]/24/10,5. Campo epigráfico: [8,5]/17,5.

CLOVTINA / [..?]+ONI $/ /[---$

Cloutina...

Alt. letras: 1. 1: 2,5/2,7; 1. 2: 2/2,2. Espaços: 1: 0/0,7; 2:0/1.

O ductus parece comprometido pela própria natureza do suporte e pela necessidade de obtenção de caracteres de módulo contido e mais ou menos regular; na 1. 1: C de recorte equilibrado, $\mathrm{L}$ de barra ligeiramente côncava, $\mathrm{O}$ quase circular, $\mathrm{V}$ de vértice arredondado, $\mathrm{T}$ bem proporcionado, I reduzido a traço vertical, $\mathrm{N}$ de hastes extremas com inclinação para a direita, A de vértice arredondado e com travessão central; na 1. 2: $\mathrm{O}$ anguloso, $\mathrm{N}$ idêntico ao da linha anterior, I definido por traço vertical, incompleto devido a ligeiro dano superficial. A letra não identificada na 1.2 pode, por hipótese, ser um R degenerado (influência cursiva) devido à dificuldade que a sua execução poderia levantar, mais uma vez, em função da natureza do suporte e do módulo escolhido; antes dela há espaço para mais dois ou, no máximo, três caracteres. A 1. 1 ocupa toda a largura do espaço epigráfico e os seus caracteres apresentam alturas ligeiramente superiores comparativamente aos da 1. 2, dando um discreto destaque ao nome da defunta. Ponto de secção circular no final da 1. 2. Ainda que a superfície do campo esteja muito desgastada, a gravação parece não ter sido muito profunda.

Cloutina é nome indígena com forte expressão regional, pois, à excepção de um testemunho em Mérida (CIL II 523 + Albertos 1966, p. 90), todos os outros se concentram no Nordeste Transmontano (Argozelo: Alves 1934, p. 33-34, n. ${ }^{\circ}$ 3) e na parte ocidental da província de Zamora (Torregamones: HEp 3, 413 + CIRPZ 199; Villar del Buey: $A E$ 1975, $520+C I R P Z$ 309). Deriva do nome indígena Cloutius, que aparece bem documentado na Astúria Meridional e na Lusitânia Oriental (cf. Untermann 1965, p. 102-103; Redentor 2000, p. 92). O radical Clout- relaciona-se com a raiz indo-europeia *kleu- 'ouvir', klutos 
'famoso' (Albertos 1966, p. 89). Com forma reduzida deste radical, documenta-se o nome Clotina (Moral de Sayago: CIL II $2617+$ CIRPZ 96), afim do que registamos e com ele coincidente geograficamente. Atentando na estrutura decorativa e na paleografia, admitimos para esta epígrafe uma cronologia do século II.

Aceitando a proposta, pormenorizada por F. S. Lemos (1993, Ib, p. 485), segundo a qual o arco montanhoso de Bornes, Navalheira e Freixo é que constituiria no Nordeste Transmontano a separação entre o conuentus Asturum e o lusitano conuentus Emeritensis, o Monte de Santa Luzia integraria este último território. Se até recentemente a opinião dos autores que aceitam esta visão convergia no facto de considerar território dos Banienses a região a sul de Bornes e da Navalheira, e entre o Tua e o Douro, a jusante da confluência do Tormes (Alarcão 1988, p. 34-35; Lemos 1993, Ib, p. 484-486), o novel estudo de C. Cruz (2000, p. 424) vem levantar a hipótese de ter existido no sector mais oriental deste território uma outra ciuitas que englobaria a zona de Freixo de Espada à Cinta, a parte sudoeste da zona de Urros e, eventualmente, parte da zona mineira de Reboredo-Carviçais, a poente. Naturalmente, este contributo científico é metodologicamente entusiasmante, mas algumas das propostas nele aventadas requerem, no futuro, um teste à sua validade, quer pela via da Arqueologia, quer pela Epigrafia.

Os achados epigráficos de que tratámos reforçam a ideia de uma ocupação da época romana no Monte de Santa Luzia e enriquecem o espólio arqueológico - já de si variado, mas no qual, por exemplo, não parecem pontuar cerâmicas de importação! — que lhe está associado. No entanto, não resolvem a questão da eventual importância excepcional do sítio. Numa leitura social, apontam para a presença de população indígena, sem estatuto jurídico privilegiado, e de quase certa origem autóctone.

\section{BIBLIOGRAFIA}

(A numeração associada às abreviaturas bibliográficas de corpora e repertórios epigráficos, salvo indicação contrária, corresponde ao n. ${ }^{\circ}$ da inscrição)

Abascal Palazón, J. M. (1994) - Los nombres personales en las inscripciones latinas de Hispania. Murcia: Universidad, Secretariado de Publicaciones; [Madrid]: 
Universidad Complutense (Arqueología; 1. Anejos de Antigüedad y cristianismo; 2).

$A E=L '$ Année Epigraphique. Paris.

AlarCão, J. de (1988) - O domínio romano em Portugal. Mem Martins: Europa-América (Forum da História; 1 ).

Albertos Firmat, M. de L. (1966) - La onomástica personal primitiva de Hispania: Tarraconense y Bética. Salamanca: Consejo Superior de Investigaciones Científicas [etc.] (Theses et studia philologica salmanticensia; 13).

Álvarez-SAnchís, J. R. (1999) — Los Vettones. Madrid: Real Academia de la Historia (Bibliotheca Archaeologica Hispana; 1).

Alves, F. M. (1934) - Memórias arqueológico-históricas do distrito de Bragança. Porto: Tip. da Emprêsa Guedes L. ${ }^{\text {da }}$ Tomo 9: arqueologia, etnografia e arte. CIL II = HüBNER, E., (1869) — Inscriptiones Hispaniae Latinae. Berolini: Gergium Reimerum (Corpus Inscriptionum Latinarum; 2).

HÜBNER, E., (1892) — Inscriptiones Hispaniae Latinae: Supplementum. Berolini: Gergium Reimerum (Corpus Inscriptionum Latinarum; 2).

CIL II ${ }^{2} / 7$ = Stylow, A. U.; GonZÁlez Román, C.; Alföldy, G. (1995) — Inscriptiones Hispaniae Latinae: Pars VII, conuentus Cordubensis. Editio altera. Berolini [etc.]: Walter de Gruyter (Corpus Inscriptionum Latinarum; 2).

CIRPS = Alonso Ávila, A.; Crespo Ortiz de ZÁrate, S. (1999) - Corpus de inscripciones romanas de la provincia de Salamanca: fuentes epigráficas para la historia social de Hispania romana. Valladolid: autores.

CIRPZ = Alonso Ávila, A.; Crespo Ortiz DE ZÁrAte, S. (2000) - Corpus de inscripciones romanas de la provincia de Zamora: fuentes epigráficas para la historia social de Hispania romana. Valladolid: autores.

CRuz, C. M. S. (2000) - A paisagem e o povoamento na longa duração: o Nordeste Transmontano - Terra Quente. Braga: [s. n.] (Tese de mestrado em Arqueologia da Paisagem, Universidade do Minho, 2000).

Fell, B. (1982) — Bronze Age America. Boston [etc.]: Little Brown.

$H A E=$ Hispania Antiqua Epigraphica . Madrid.

HEp = Hispania Epigraphica . Madrid.

ILER = VIVES, J. (1971-1972) — Inscripciones latinas de la España Romana: antología de 6.800 textos. Barcelona: Universidad [etc.]. 2 vols.

"LAMINAK" in Encyclopedia Mythica [em linha]. [s. 1.]: MMI Encyclopedia Mythica, (revisto em 12 de Agosto de 2001) [citado em 29 de Agosto de 2001 - 18:00]. Disponível em URL:

Lemos, F. S. (1993) - O povoamento romano de Trás-os-Montes Oriental. Braga: [s. n.] (Tese de doutoramento em Pré-História e História da Antiguidade, Universidade do Minho, 1993).

Marques, J. A. M. (1991) - Materiais para a Arqueologia do concelho de Freixo de Espada à Cinta. Revista da Faculdade de Letras: História. Porto. 2. ํㅜ série. 8, p. 393-409. 
Mourinho, A. M. (1986) - Epigrafia latina de entre Sabor e Douro desde o falecimento do Abade de Baçal — 1947. Brigantia. Bragança. 6:1-3, p. 3-36.

PALOMAR LAPESA, M. (1957) — La onomástica personal pre-latina de la antigua Lusitania: estudio lingüístico. Salamanca: Consejo Superior de Investigaciones Científicas [etc.] (Theses et studia philologica salmanticensia; 10).

Redentor, A. (2000) - Epigrafia romana da região de Bragança. Coimbra: [s. n.] (Tese de mestrado em Arqueologia, Universidade de Coimbra, 2000).

Santos Júnior, J. R. (1963) — "Berrõezinhos" do Castro de Santa Luzia (Freixo de Espada-à-Cinta). In Genovés TArazaga, S., ed. - A Pedro Bosch-Gimpera: en el septuagésimo aniversario de su nacimiento. México: Instituto Nacional de Antropología e Historia. p. 395-402.

SANTOS Júnior, J. R. (1975) - A cultura dos berrões no Nordeste de Portugal. Trabalhos de Antropologia e Etnologia. Porto. 22:4, p. 353-516.

SANTOS JúnIOR, J. R. (1977) — Novos elementos da remota zoolatria em Trás-os-Montes. Trabalhos de Antropologia e Etnologia. Porto. 23:1, p. 5-28.

SANTOS Júnior, J. R. (1978) - Mais um berrão da zona do castro do Monte de Santa Luzia (Freixo de Espada-à-Cinta). Trabalhos de Antropologia e Etnologia. Porto. 23:2-3, p. 333-340.

SANTOS JúnIOR, J. R. (1981) — Mais três berrões proto-históricos de Freixo de Espada-à-Cinta. Trabalhos de Antropologia e Etnologia. Porto. 24:1, p. 101-120.

SANTOS Júnior, J. R. (1983) — A remota zoolatria e a lápide do Castro do Monte de St. ${ }^{\text {a }}$ Luzia (Freixo de Espada-à-Cinta). Trabalhos de Antropologia e Etnologia. Porto. 24:3, p. 526-532.

SANTOS JúnIOR, J. R. (1985) — A cultura dos berrões proto-históricos fundamente radicada em Trás-os-Montes. Trabalhos de Antropologia e Etnologia. Porto. 25:1, p. 31-40.

Silva, A. C. F. da (1986) - A cultura castreja no Noroeste de Portugal. Paços de Ferreira: Câmara Municipal, Museu Arqueológico da Citânia de Sanfins.

Untermann, J. (1965) - Elementos de un atlas antroponimico de la Hispania antigua. Madrid: Consejo Superior de Investigaciones Científicas, Instituto Español de Prehistoria [etc.] (Bibliotheca Praehistorica Hispana; 7). 
EST. I

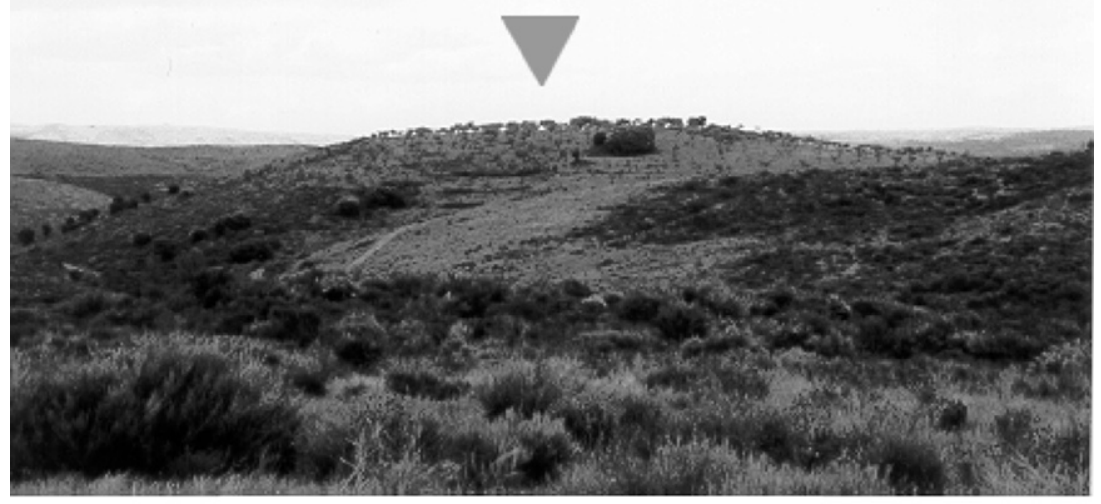

Fото 1 - Monte de Santa Luzia (vista sul)

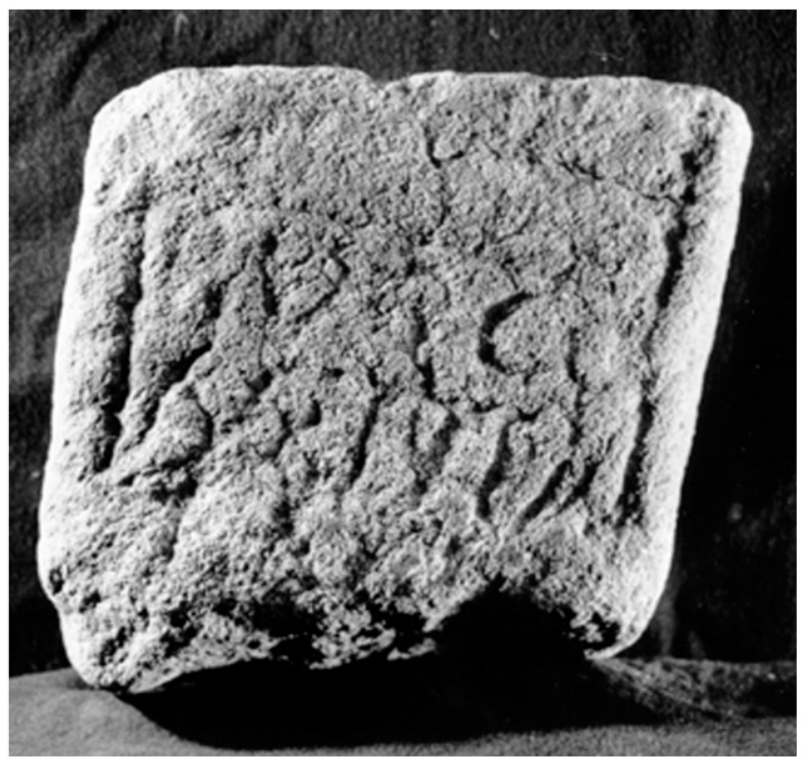

Fото 2 - Epígrafe A (epitáfio de Bucão) 
EST. II

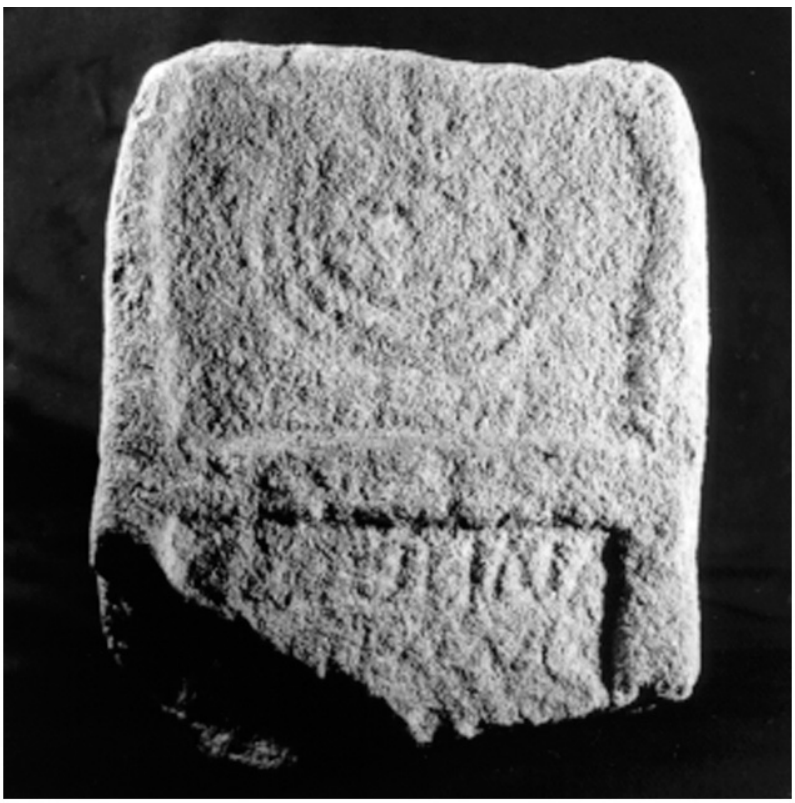

Fото 3 - Epígrafe B (epitáfio de Cloutina)

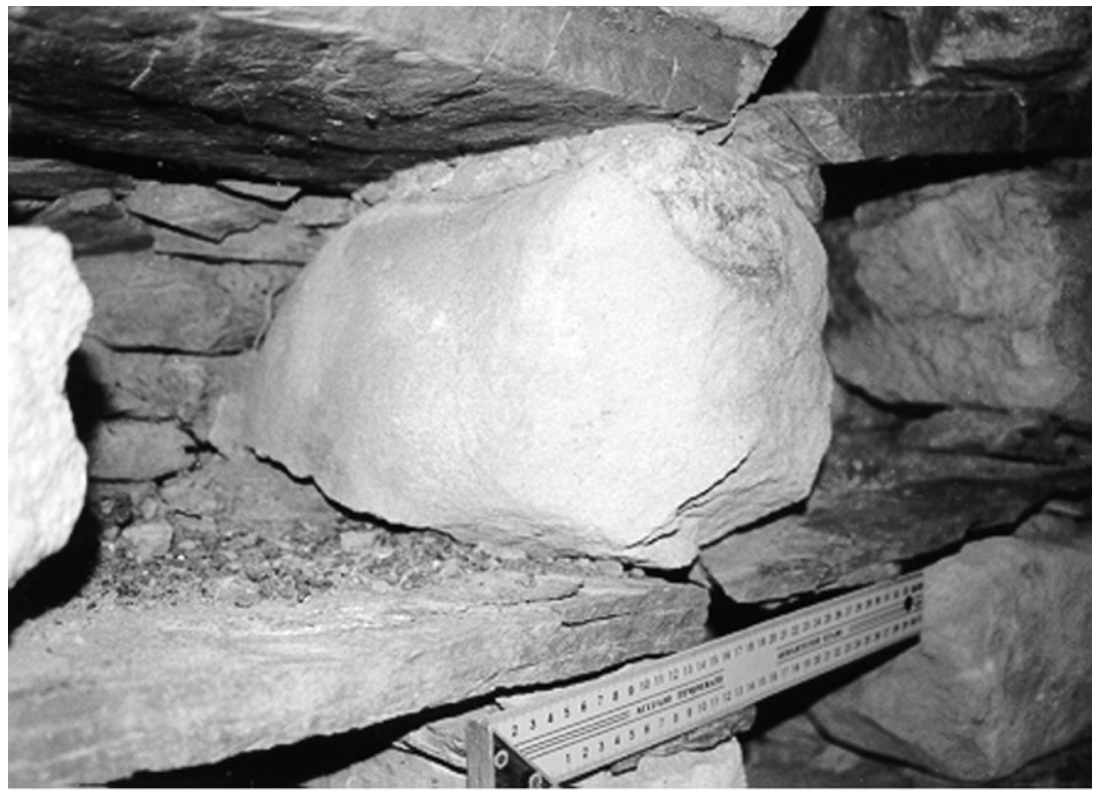

Fото 4 - Berrão incompleto reaproveitado no interior do pombal 